\title{
Theoretical and Experimental Analysis on Wellbore Enhancement in Fractured Formation through Tight Fracture Plugging by Drilling Fluid
}

\author{
Junyi Liu \\ Drilling Technology Research Institute of SINOPEC Shengli Oilfield Service Corporation, Dongying 257100, China
}

Corresponding Author Email: danielliu1988@126.com

https://doi.org/10.18280/ti-ijes.630113

Received: 8 January 2019

Accepted: 20 March 2019

\section{Keywords:}

wellbore enhancement, wellbore pressure (WP) containment, tight fracture plugging (TFP) zone, subsurface formation, drilling fluids

\begin{abstract}
With the aim to prevent lost circulation and wellbore instability in drilling, this paper probes deep into the wellbore enhancement mechanism and tight fracture plugging (TFP), and simulates the performance of different drilling fluids. First, the wellbore enhancement mechanism of stress cage technique, which improves wellbore pressure (WP) containment, was investigated through ABAQUS finite-element modeling. It was found that WP containment could be enhanced by improving the drilling fluid plugging or propping of existing or new fractures, which curbs fracture propagation and increases hoop stress of the wellbore. Moreover, a physical model of the TFP zone was established, revealing the microscale plugging mechanism. On this basis, the author put forward a way to optimize the TFP drilling fluid and thus the WP containment: creating a TFP zones with a strong force chain network from the rigid and resilient particles of reasonable type and size distribution and fibers. In addition, a novel simulation device was designed to evaluate and simulate the dynamic plugging features of drilling fluid, and used to optimize the enhanced TFP formulas for drilling fluid at wedge fractures of different widths. The optimized formulas can improve the loss-prevention of drilling fluid and significantly boost the WP containment in subsurface formation.
\end{abstract}

\section{INTRODUCTION}

Nowadays, oil and gas reservoirs with complex geology have entered the scope of exploration, such as deep or ultradeep unconventional water reservoirs. This trend gives rise to several serious problems (e.g. repetitive loss, formation loss and overflow and wellbore collapse), calling for better drilling fluid technology [1-4]. To control lost circulation in subsurface formation, the mechanisms and materials of loss prevention like drilling fluid have been extensively explored through simulation and experiment. Below is a brief introduction to some of the representative studies.

Morita et al. [5] and Messenger et al. [6] adjusted the nearwellbore stress state through fracture plugging and propping, thereby enhancing the wellbore pressure (WP) containment in a subsurface formation. Aston et al. [7] discussed the mechanism and influencing factors of the stress cage technique, aiming to enhance the WP containment of subsurface formation. Wang et al. [8 13] developed a fracture plugging and propping method based on boundary element method (BEM), and examined how this mechanism boosts the WP containment in a subsurface formation. Focusing on a subsurface formation, Van Oort et al. [14] compared several new wellbore enhancement techniques that improve the WP containment, and concluded that the improvement requires the increase in the fracture propagation pressure. Using statistics on lost circulation in northeast Sichuan, China, Cai et al. [15] analyzed the influencing factors of the WP containment in subsurface formation. Kang et al. [16] reviewed the theories and methods for enhancing WP containment in subsurface formation, and determined the application environment of different theories. Inspired by the fundamental theories on rock fracture mechanics, Wang et al. and Jia et al. [17-19] determined the mechanisms for loss prevention that obstructs fracture propagation. Kumar et al. [20-22] compared the effects of several loss prevention materials on fracture plugging amelioration. Loeppke et al. and Kaageson-Loe et al. [23-24] theoretically analyzed how the size of plugging material affects the fracture plugging mode, and verified the theoretical results through experiments on a novel simulation device for fracture plugging.

Overall, the drilling fluid for loss prevention has been successfully adopted across the world to promote the WP containment in subsurface formation. However, there is still much room to improve the microscale mechanism, simulation evaluation and application scope. In this paper, the wellbore enhancement mechanism of the stress cage is analyzed through ABAQUS finite-element modeling, and the loss prevention material is characterized in details to disclose and improve how drilling fluid plugs tight factures. In addition, a novel simulation device was designed to evaluate and simulate the dynamic plugging features of drilling fluid, and used to optimize the enhanced tight fracture plugging (TFP) formulas for drilling fluid at wedge fractures of different widths. The optimized formulas can improve the loss-prevention of drilling fluid and significantly boost the WP containment in subsurface formation. 


\section{ANALYSIS ON WELLBORE ENHANCEMENT MECHANISM}

\subsection{Wellbore enhancement model}

Our wellbore enhancement model was established based on the stress cage theory. The subsurface rock was assumed as homogenous, isotropic, linearly elastic and deformable, simplifying the wellbore enhancement into the optimization of axisymmetric plane strain. Based on the finite-element software ABAQUS, a fracture-free model and a fractured model were constructed to analyze the wellbore enhancement mechanism. The stress variations near the wellbore and fracture widths were investigated under such states as fracture initiation, fracture propagation and fracture plugging/bridging, followed by the discussion of the influencing factors like stress anisotropy, WP and bridging location on wellbore enhancement. The research findings lay a theoretical basis for loss prevention with drilling fluid. The basic parameters of wellbore enhancement are listed in Table 1 below.

Table 1. Basic parameters of wellbore strengthening model

\begin{tabular}{ccccccc}
\hline $\begin{array}{c}\text { Model Size } \\
/ \mathrm{m}\end{array}$ & $\begin{array}{c}\text { Wellbore Radius } \\
\mathrm{D} / \mathrm{m}\end{array}$ & $\begin{array}{c}\text { Elastic Modulus } \\
\mathrm{E} / \mathrm{GPa}\end{array}$ & Poisson's Ratio & $\begin{array}{c}\mathrm{S}_{\mathrm{h}} \\
/ \mathrm{MPa}\end{array}$ & $\begin{array}{c}\mathrm{S}_{\mathrm{H}} \\
/ \mathrm{MPa}\end{array}$ & $\begin{array}{c}\text { Fracture Length } \\
\mathrm{L}_{\mathrm{f}} / \text { in }\end{array}$ \\
\hline $1 \times 1$ & 0.1 & 7.52 & 0.25 & 20.7 & $\mathrm{~S}_{\mathrm{h}} \& 2 \mathrm{~S}_{\mathrm{h}} \& 3 \mathrm{~S}_{\mathrm{h}}$ & 6 \\
\hline
\end{tabular}

\subsection{Influencing factors on wellbore enhancement}

The wellbore enhancement directly hinges on the stress state near the wellbore. In this paper, the boundary conditions and loads of the established model are adjusted to simulate how each of the influencing factors, namely, stress anisotropy, bridging location and WP, and affects the wellbore stress and fracture width. The simulation system is depicted in Figure 1, where the horizontal angle of the fracture line increases gradually from zero to $90^{\circ}$ counterclockwise. Note that the tensile stress was defined as negative and the compressive stress as positive.

(1) Stress anisotropy

Considering the complex states of anisotropic stress in subsurface formation, the minimum horizontal principal stress $\mathrm{S}_{\mathrm{h}}$ was set as a constant and the maximum horizontal principal stress $\mathrm{S}_{\mathrm{H}}$ was simulated as $\mathrm{S}_{\mathrm{h}}, 2 \mathrm{~S}_{\mathrm{h}}$ and $3 \mathrm{~S}_{\mathrm{h}}$, respectively, to disclose the impact of stress anisotropy on the wellbore stress and fracture pattern. The simulation results in Figure 2 show that, compared with the fracture-free wellbore stress, the hoop stress $\left(\mathrm{S}_{\mathrm{ho}}\right)$ of the wellbore increased sharply after fracture propagation and bridging, and the most prominent growth was observed in the horizontal angle of $0 \sim 30^{\circ}$; the wellbore stress far from the fracture zone $\left(50 \sim 90^{\circ}\right)$ after plugging/bridging had no increase and even a slight decline from that after fracture propagation. In general, the hoop stress growth is positively correlated with the stress anisotropy $\left(\mathrm{S}_{\mathrm{H}}=3 \mathrm{~S}_{\mathrm{h}}\right)$. It can be seen from Figure 2 that the wellbore stress was redistributed after plugging/bridging. As a result, the subsurface formation underwent changes in the pressure for initiation and reopening of fractures, and the fracture initiation point moved constantly around the wellbore.

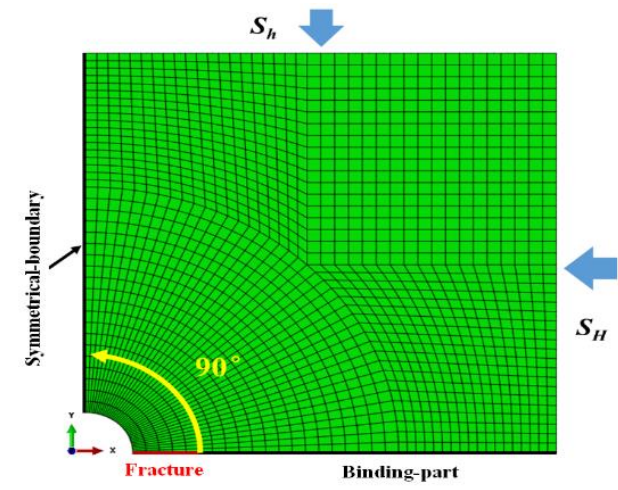

Figure 1. Boundary conditions of wellbore strengthening model

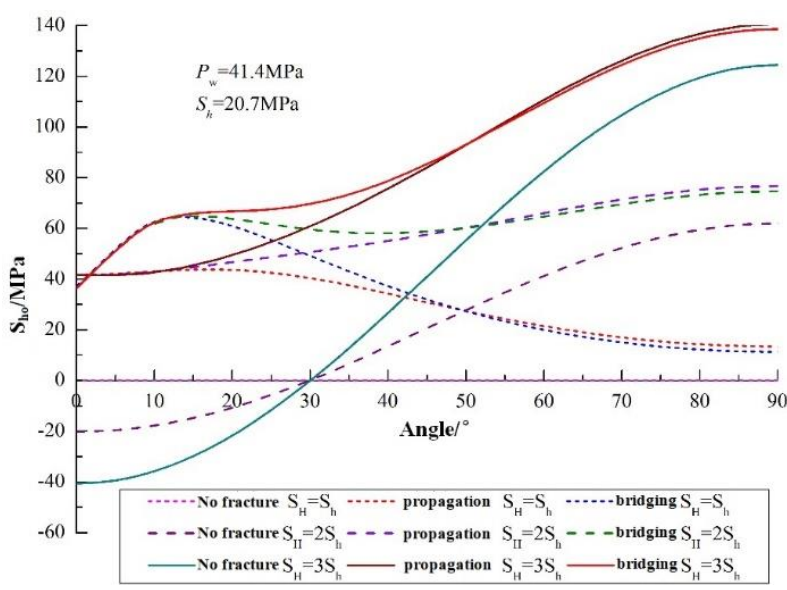

Figure 2. Hoop stress distribution for different stress anisotropies

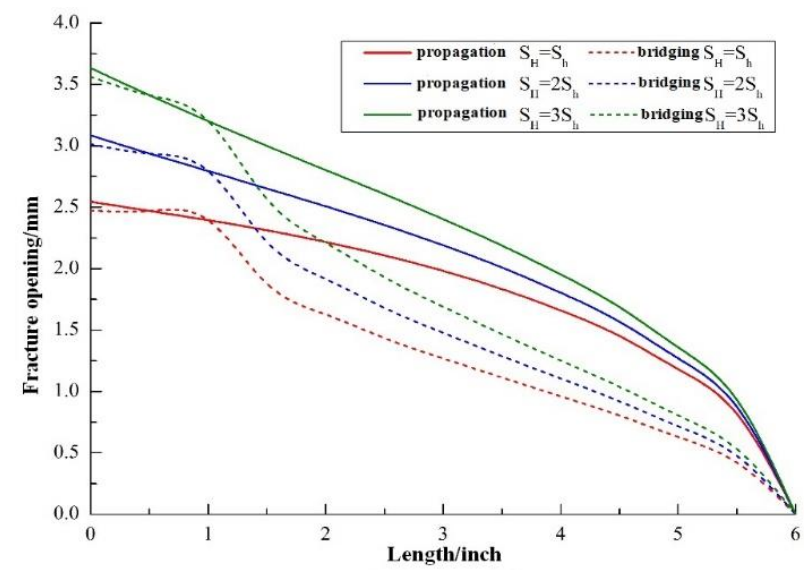

Figure 3. Fracture opening before and after bridging under different stress anisotropies

Figure 3 describes the relationship between stress anisotropy and fracture width. As shown in the figure, the stress anisotropy increased after fracture propagation and bridging, leading to larger fracture widths. During fracture propagation and bridging, the fracture widths at the initiation point were almost the same, indicating that the wellbore was fully supported by the TFP zone formed by the loss prevention material. In fact, the TFP is comparable to the fluid compaction effect within the fractures on the wellbore. Meanwhile, the fracture width in the fracture isolation zone was reduced as the fracture pressure leaked into the rock 
matrix. Moreover, the large sustained widths after fracture bridging indicates an increased squeezing effect in this zone, and the additional hoop stress further enhanced the wellbore. These phenomena agree well with the simulated results in Figure 2: stress anisotropy does affect wellbore enhancement effect.

(2) Bridging location

To disclose the impact of bridging location on wellbore enhancement, the boundary conditions of the nodes in our model were adjusted to simulate the bridging/propping effect of the loss prevention material at different locations, respectively $0.5^{\prime}, 1$ ', 2' and 3' away from the wellbore. The pressure at the front of the bridge within the fracture was maintained at the same level as the WP. As can be seen from the simulation results in Figure 4, the hoop stress of wellbore rocketed up after bridging occurred at any of the three locations, and the greatest increment was seen at $0.5^{\prime}$. The increment exhibited a gradual decline as the location approached the fracture tip. When bridging happened at 2' or 3', the hoop stress of the wellbore only showed a minor variation. This means the wellbore enhancement effect of bridging is positively correlated with the location to the wellbore.

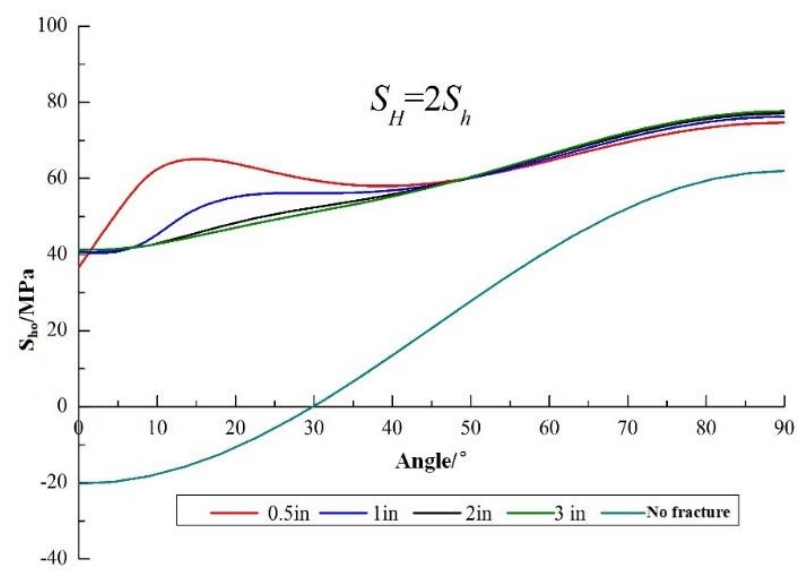

Figure 4. Hoop stress distribution for different bridging locations

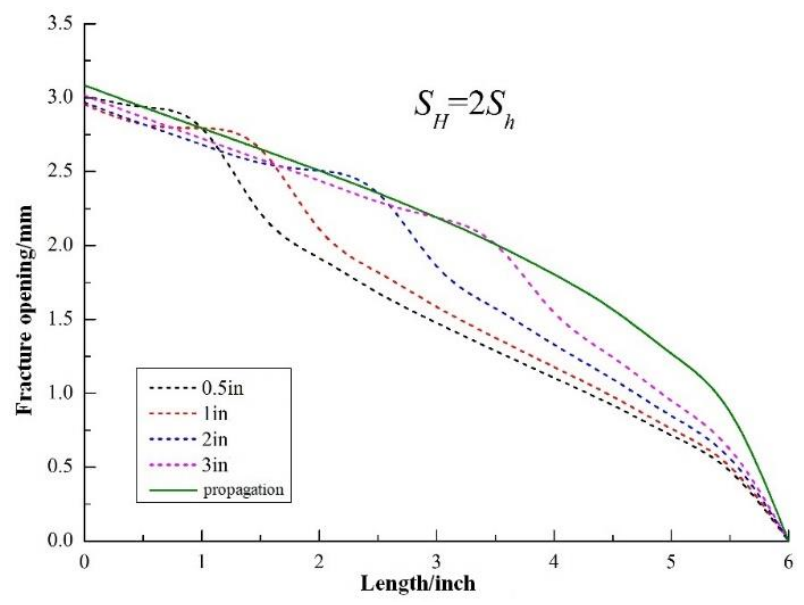

Figure 5. Fracture opening for different bridging locations

(3) Wellbore pressure

If the subsurface formation has pre-existing fractures, most of which are closed ones, it will require much less pressure to reopen the fractures than initiate new fractures. Considering this, the fracture reopening was simulated in our model at the WPs of $41.4 \mathrm{MPa}(2 \mathrm{Sh}), 31.1 \mathrm{MPa}(1.5 \mathrm{Sh})$ and $20.7 \mathrm{MPa}(\mathrm{Sh})$, with the aim to reveal the influence of WP on wellbore enhancement. As shown in Figure 6, the hoop stress of the wellbore presented a growing trend under the wellbore pressure of $41.4 \mathrm{MPa}$, and the growth was the most obvious within the low angle range $\left(0 \sim 30^{\circ}\right)$. With the decline in the WP, the hoop stress of the wellbore plunged deeply, and the wellbore enhancement gradually diminished after fracture propagation and bridging. It can be seen from Figure 7 that the fracture width was relatively small when the WP was lower than $41.4 \mathrm{MPa}$. A possible reason is that the fluid flowing into the fracture is not severely pressurized under a low wellbore pressure. In this case, the fluid exerts a weak squeezing effect on both sides of the fractures, leading to a small fracture width. To sum up, a low WP pressure cannot significantly enhance the wellbore in the pre-fractured subsurface formation, due to the weak squeezing effect of the fluid on the wellbore.

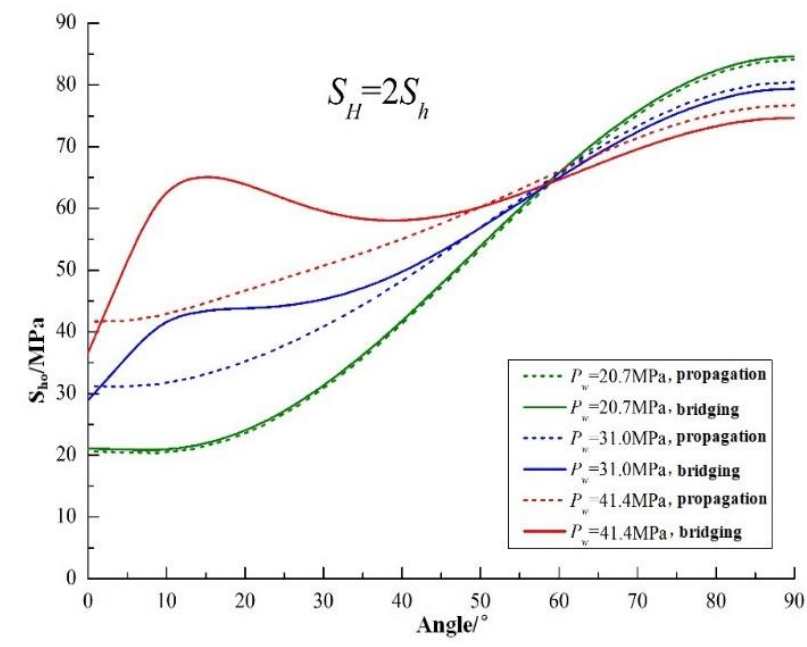

Figure 6. Hoop stress distribution for different wellbore pressures

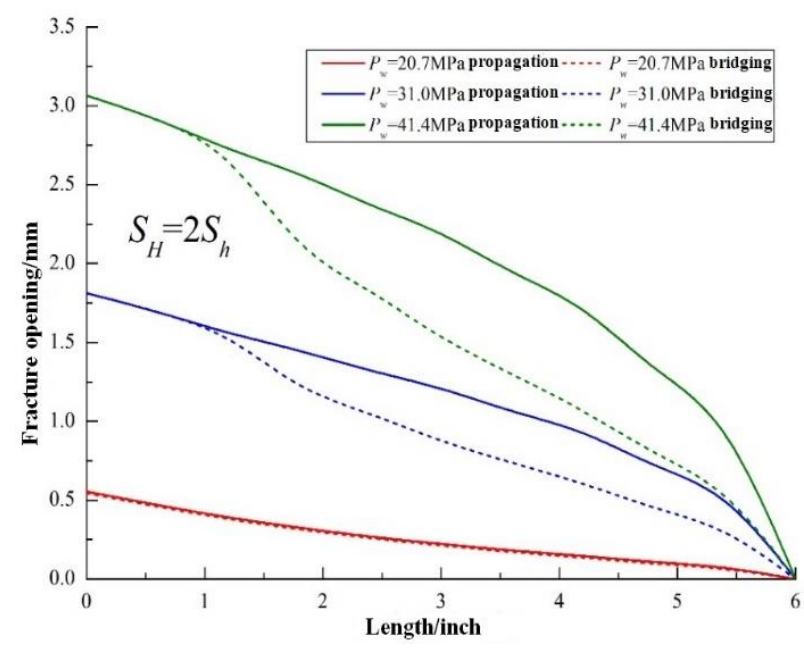

Figure 7. Fracture opening for different wellbore pressures

\subsection{Wellbore enhancement mechanism}

The wellbore enhancement mechanism that enhances WP containment was investigated comprehensively based on the above analysis on the wellbore enhancement model and the influencing factors. It can be concluded that the WP 
containment of pre-fractured subsurface formation is significantly enhanced by the plugging effect of drilling fluid. The fluid can rapidly and effectively bridge or plug fractures near the initiation point. The resulting pressure isolation at the fracture tip prevents the fractures from elongation and propagation. For a newly formed TFP zone, the hoop stress of the wellbore will be enhanced by propping the fractures to the designed width. In this way, the WP in the subsurface formation can be contained well, creating a larger density range of drilling fluid. To promote the WP containment in subsurface formation, the key lies in plugging leakage fractures, propping fractures to the designed width, and boosting the hoop stress of the wellbore.

However, these key measures only take effect in intact or slightly fractured rock masses. For example, the wellbore can be enhanced significantly through these measures in permeable sands or similar formation. In fractured formations like bio-limestone and coal rock, however, it may be necessary to introduce chemical plugging to enhance the wellbore. When it comes to impermeable shale gas formation, nanotechnology must be adopted to process the drilling fluid for enhancing wellbore in such formation based on the microstructural features of gas-shale.

\section{SIMULATION EXPERIMENT}

As the basis for fracture plugging drilling fluid, the loss prevention material should be optimized, forming TFP zone with a strong force chain network [25-27]. The strong force chain principle is an important concept in granular matter mechanics, an emerging science involving multiple disciplines and analysis scales. In fact, granular matter mechanics mainly tackles the interaction among numerous discrete particles, as well as the stationary and dynamic laws of complex particle systems [28-29]. In this paper, the microscale TFP mechanism of drilling fluid is determined according to the said principle, so is the optimization method for drilling fluid TFP. Then, a simulation device was created to evaluate the plugging features of drilling fluid, and optimize the enhanced TFP formulas for drilling fluid at the wedge fractures with different widths.

\subsection{Microscale TFP mechanism}

According to the strong force chain principle in granular matter mechanics, the force chain network of TFP zone, a typical particle system, was constructed based on the interface force on the microscale to control the microscopic mechanics of the zone. In light of the features of the loss prevention material, a physical model of TFP zone was established to examine the microscale TFP mechanism, giving birth to a TFP optimization method for drilling fluid.

Specifically, the rigid and resilient particles of reasonable type and size distribution were used in synergy with fibers for fracture plugging, producing a strong force chain network of TFP zone. The different materials play varied roles in the wellbore enhancement process. The rigid particles could bridge easily at pore throats or fractures, and thus provide the basis for the TFP framework; the resilient particles could automatically fill the pores between the rigid particles under the combined effect of extrusion deformation and elastic rebound, and also bolster the self-adaptive plugging ability of TFP zone to the varying fracture width in different wellbore stress states; the fibers could further fill the pore in the TFP zone, turning the particles into a strong force chain network and creating a TFP zone with high compactness, stability and volume fraction.

\subsection{Simulation device}

Despite its critical importance, there is not yet a universal simulation device for plugging feature analysis on drilling fluid [30]. The conventional devices, ranging from DL-1, JLX2 to HTHP plugging simulators [31-35] could only simulate fluid loss and fracture plugging under a fixed fracture width, failing to address dynamic and variable fracture widths. To solve the problem, the author developed a novel simulation device for the plugging features of drilling fluid [36]. The design aims to simulate the loss and plugging of fractures with varied widths under different formation pressures and temperatures, and capture the real-time values of following parameters: fluid loss rate, TFP zone pressure containment, and fracture width variation.

The proposed simulation device consists of four parts, namely, fracture simulation system, drilling fluid circulation system, temperature and pressure control system, plus data acquisition system. During the simulation, the pressure was controlled between 0 and $60 \mathrm{MPa}$, and measured with an accuracy of $0.25 \% \mathrm{FS}$ (full scale); the temperature was controlled between room temperature and $160{ }^{\circ} \mathrm{C}$, and measured with an accuracy of $0.5{ }^{\circ} \mathrm{C}$; the flow rate was controlled between 0 and $25 \mathrm{~mL} / \mathrm{min}$, and measured with an accuracy of $0.05 \mathrm{~mL} / \mathrm{min}$; the fracture width was controlled between 0 and 3,000 $\mu \mathrm{m}$, and measured with an accuracy of $0.05 \% \mathrm{FS}$ (full scale).

\subsection{Optimization of enhanced TFP formulas}

Repetitive fluid loss is commonplace in drilling operations, for the fracture width changes dynamically from tens to hundreds or millions of micrometers under different wellbore pressures [37]. Owing to the wide fractures and high loss rate of fluid, it is difficult to form TFP zone near the fracture opening, especially millimeter fractures. This calls for urgent improvement to the WP containment in subsurface formation with drilling fluid. Moreover, the previous studies have shown that the formation fracture morphology can be characterized accurately as the wedge shape. As shown in Figure 8, the wedge shape fracture becomes narrower from the fracture opening towards the fracture tip [38-39]. Therefore, this shape was adopted for the optimization of our enhanced TFP formulas.

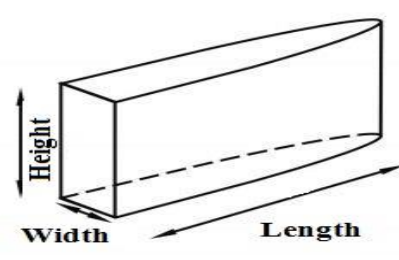

Figure 8. Schematic of wedge shape fracture profiles

In light of the above, the enhanced TFP formulas for millimeter-scale wedge shape fractures $(3 \mathrm{~mm} \times 2 \mathrm{~mm}$, $2 \mathrm{~mm} \times 1 \mathrm{~mm}$ and $1 \mathrm{~mm} \times 0.5 \mathrm{~mm}$ ) were optimized according to the TFP mechanism of drilling fluid. Then, a TFP zones with a strong force chain network was created from the rigid and 
resilient particles of reasonable type and size distribution and fibers, such as nutshell particle (NUT), calcite particle (RIG), rubber particle (RUB) and fiber (FIB). To optimize the particle size distribution of loss prevention material, the particle size distribution of the material was divided into five categories, denoted as $0 \sim \mathrm{IV}$. Any particle smaller than $0.2 \mathrm{~mm}$ was not further divided. The division standard is explained in Table 2.

Table 2. Classification standard of particle size distribution

\begin{tabular}{cccccc}
\hline Type & 0 & I & II & III & IV \\
\hline Mesh & $6 \sim 10$ & $10 \sim 20$ & $20 \sim 40$ & $40 \sim 80$ & $>80$ \\
Size/mm & $3.2 \sim 2.0$ & $2.0 \sim 0.9$ & $0.9 \sim 0.45$ & $0.45 \sim 0.2$ & $<0.2$ \\
\hline
\end{tabular}

\subsection{Results analysis}

The optimized TFP formula for $3 \mathrm{~mm} \times 2 \mathrm{~mm}$ wedge shape fractures is presented in Table 3. Obviously, the TFP zone formed by RIG alone was typically loose, with the pressure containment of $3 \mathrm{MPa}$ and fluid loss volume of $200 \mathrm{~mL}$. The addition of RUB in different sizes partially enhanced the stability of the TFP zone, pushing up the pressure containment to $5 \mathrm{MPa}$, but the fluid loss volume remained large $(230 \mathrm{~mL})$. After the FIB had been added to the RIG and RUB, the TFP zone was turned into a strong force chain network, which saw the pressure containment growing to $8 \mathrm{MPa}$ and fluid loss volume falling to $90 \mathrm{~mL}$.

Table 3. Optimization results of the tight fracture plugging formula for $3 \mathrm{~mm} \times 2 \mathrm{~mm}$ wedge shape fractures

\begin{tabular}{|c|c|c|c|c|c|c|c|c|c|c|c|}
\hline Materials & Formula & \multicolumn{10}{|c|}{ Experimental data } \\
\hline \multirow{2}{*}{ Rigid } & \multirow{2}{*}{$\begin{array}{c}5 \% \text { NUT- } 0+5 \% \text { RIG-I + 3\%RIG-II+ } \\
4 \% \text { RIG-III + 1\%RIG-IV } \\
\end{array}$} & $\mathrm{P} / \mathrm{MPa}$ & 0 & 1.0 & 2.0 & 3.0 & 4.0 & 5.0 & 6.0 & 7.0 & 8.0 \\
\hline & & $\mathrm{V} / \mathrm{mL}$ & 80 & 120 & 140 & 200 & All & 1 & 1 & 1 & 1 \\
\hline \multirow{2}{*}{$\begin{array}{l}\text { Rigid and } \\
\text { resilient }\end{array}$} & \multirow{2}{*}{$\begin{array}{c}5 \% \text { NUT-0 + 5\%RIG-I + 3\%RIG-II } \\
+0.5 \% \text { RUB-II + 4\%RIG-III + } \\
0.5 \% \text { RUB-III + 1\%RIG-IV }\end{array}$} & $\mathrm{P} / \mathrm{MPa}$ & 0 & 1.0 & 2.0 & 3.0 & 4.0 & 5.0 & 6.0 & 7.0 & 8.0 \\
\hline & & $\mathrm{V} / \mathrm{mL}$ & 45 & 145 & 160 & 160 & 160 & 230 & All & I & I \\
\hline \multirow{2}{*}{$\begin{array}{l}\text { Rigid and } \\
\text { resilient } \\
\text { and fiber }\end{array}$} & \multirow{2}{*}{$\begin{array}{c}5 \% \text { NUT- } 0+5 \% \text { RIG-I }+3 \% \text { RIG-II } \\
+0.5 \% \text { RUB-II }+4 \% \text { RIG-III + } \\
0.5 \% \text { RUB-III }+1 \% \text { RIG-IV }+ \\
0.3 \% \text { FIB }\end{array}$} & $\mathrm{P} / \mathrm{MPa}$ & 0 & 1.0 & 2.0 & 3.0 & 4.0 & 5.0 & 6.0 & 7.0 & 8.0 \\
\hline & & $\mathrm{V} / \mathrm{mL}$ & 18 & 55 & 85 & 85 & 85 & 85 & 90 & 90 & 90 \\
\hline
\end{tabular}

Table 4. Optimization results of the tight fracture plugging formula for $2 \mathrm{~mm} \times 1 \mathrm{~mm}$ and $1 \mathrm{~mm} \times 0.5 \mathrm{~mm}$ wedge shape fractures

\begin{tabular}{|c|c|c|c|c|c|c|c|c|c|c|c|}
\hline Width/mm & \multirow{3}{*}{$\begin{array}{c}\text { Formula } \\
3 \% \text { RIG-I }+2 \% \text { NUT-I }+ \\
2 \% \text { RIG-II + } 0.5 \% \text { RUB-II + } \\
3 \% \text { RIG-III + } 0.5 \% \text { RUB-III + } \\
1 \% \text { RIG-IV + } 0.2 \% \text { FIB }\end{array}$} & \\
\hline \multirow[b]{2}{*}{$2 \times 1$} & & \multicolumn{9}{|c|}{$\begin{array}{l}\text { Experimental data } \\
\begin{array}{cccc}2.0 & 3.0 & 4.0 & 5.0\end{array}\end{array}$} & 8.0 \\
\hline & & $\mathrm{V} / \mathrm{mL}$ & 6 & 20 & 20 & 20 & 22 & 22 & 22 & 22 & 22 \\
\hline \multirow[b]{2}{*}{$1 \times 0.5$} & $2 \%$ RIG-II + 0.5\%RUB-II + & $\mathrm{P} / \mathrm{MPa}$ & 0 & 1.0 & 2.0 & 3.0 & 4.0 & 5.0 & 6.0 & 7.0 & 8.0 \\
\hline & $\begin{array}{c}3 \% \text { RIG-III + 0.5\%RUB-III + } \\
1 \% \text { RIG-IV + 0.1\%FIB }\end{array}$ & $\mathrm{V} / \mathrm{mL}$ & 0 & 0 & 0 & 0 & 0 & 5 & 5 & 5 & 5 \\
\hline
\end{tabular}

Table 5. Self-adapting evaluation on strengthened tight plugging formulas

\begin{tabular}{|c|c|c|c|c|c|c|c|c|c|c|c|}
\hline Formula & Width/mm & \multicolumn{10}{|c|}{ Experimental data } \\
\hline \multirow{6}{*}{$\begin{array}{c}5 \% \text { NUT-0 + 5\%RIG-I + } \\
3 \% \text { RIG-II + 0.5\%RUB-II } \\
+4 \% \text { RIG-III + } \\
0.5 \% \text { RUB-III + } 1 \% \text { RIG- } \\
\text { IV + } 0.3 \% \text { FIB }\end{array}$} & \multirow{2}{*}{$2 \times 1 / 1 \times 0.5$} & $\mathrm{P} / \mathrm{MPa}$ & 0 & 1.0 & 2.0 & 3.0 & 4.0 & 5.0 & 6.0 & 7.0 & 8.0 \\
\hline & & $\mathrm{V} / \mathrm{mL}$ & 4 & 16 & 20 & 28 & 38 & 40 & 40 & 40 & 40 \\
\hline & \multirow{2}{*}{$3 \times 2 / 1 \times 0.5$} & $\mathrm{P} / \mathrm{MPa}$ & 0 & 1.0 & 2.0 & 3.0 & 4.0 & 5.0 & 6.0 & 7.0 & 8.0 \\
\hline & & $\mathrm{V} / \mathrm{mL}$ & 30 & 58 & 90 & 90 & 90 & 105 & 105 & 110 & 110 \\
\hline & \multirow{2}{*}{$3 \times 2 / 2 \times 1$} & $\mathrm{P} / \mathrm{MPa}$ & 0 & 1.0 & 2.0 & 3.0 & 4.0 & 5.0 & 6.0 & 7.0 & 8.0 \\
\hline & & $\mathrm{V} / \mathrm{mL}$ & 38 & 75 & 90 & 90 & 90 & 110 & 110 & 130 & 130 \\
\hline
\end{tabular}

Meanwhile, the TFP formulas for $2 \mathrm{~mm} \times 1 \mathrm{~mm}$ and $1 \mathrm{~mm} \times 0.5 \mathrm{~mm}$ wedge shape fractures were optimized by the same method. The results in Table 4 show that the pressure containment of the TFP zone increased to $8 \mathrm{MPa}$ with a smaller fluid loss volume.

In lab tests, a typical fracture width was often selected to optimize the TFP formulas. Since the fracture width is highly variable in actual subsurface formation, the TFP formulas should be adaptive to the actual condition. Hence, the adaptability of the formulas was evaluated using wedge shape fractures of two representative width on the same fracture model. The results are recorded in Table 5. It can be seen that TFP formula for $3 \mathrm{~mm} \times 2 \mathrm{~mm}$ wedge shape fractures adapted to different widths with pressure resistance up to $8 \mathrm{MPa}$, thus improving loss-prevention ability of drilling fluid and enhancing WP containment of subsurface formation.

\section{CONCLUSIONS}

This paper probes into the wellbore enhancement mechanism through ABAQUS finite-element modelling. It was found that WP containment could be enhanced by improving the drilling fluid plugging or propping of existing or new fractures, which curbs fracture propagation and increases hoop stress of the wellbore. Moreover, a physical model of the TFP zone was established, revealing the microscale plugging mechanism. On this basis, the author put forward a way to optimize the TFP drilling fluid and thus the WP containment: creating a TFP zones with a strong force chain network from the rigid and resilient particles of reasonable type and size distribution and fibers.

The enhanced TFP formulas were also optimized for drilling fluid for wedge fractures with different widths. Simulation shows that these formulas guarantee good 
adaptability to different fractures width with pressure resistance up to $8 \mathrm{MPa}$. In this way, the drilling fluids acquired much stronger loss prevention ability, and bolster the WP containment of subsurface formation. The research results shed new light on the optimization of TFP drilling fluid.

\section{ACKNOWLEDGEMENTS}

We would like to thank the financial support from China Postdoctoral Science Foundation (2017M612344), Shandong province post-doctoral innovation projects (201703044).

\section{REFERENCES}

[1] Li Y, Jin Q, Zhong JH, Zou SZ. (2016). Karst zonings and fracture-cave structure characteristics of Ordovician reservoirs in Tahe oilfield. Tarim Barin. Acra Pereolei $\begin{array}{lll}\text { Sinica } & 37(3): & 289-298 .\end{array}$ https://doi.org/10.7623/syxb201603001

[2] Fu JH, Feng J, Chen P, Wei HS, Liu ZL. (2015). Simulation on wellbore pressure during dynamic kill drilling in deep water. Acra Pereolei Sinica 36(2): 232 237. https://doi.org/10.7623/syxb201502013

[3] Sun ZD, Jia CZ, Li XF. (2011). Unconventional oil \& gas exploration and development (upper volume). Petroleum Industry Press.

[4] Wu C, Chen XF, Wang L. (2016). A theory on predicting drilling fluid density windows while drilling and its engineering application. Acra Pereolei Sinica 37(3): 399405. https://doi.org/10.7623/syxb201603012

[5] Morita N, Black AD, Fuh GF. (1990). Theory of lost circulation pressure. SPE Annual Technical Conference and Exhibition 43-58. https://doi.org/10.2118/20409-MS

[6] Messenger JU. (1981). Lost circulation. Pennwell Publishing Company.

[7] Aston MS, Alberty MW, McLean MR, de Jong HJ, Armagost K. (2004). Drilling fluids for wellbore strengthening. IADC/SPE Drilling Conference Proceedings of the Drilling Conference 321-328. https://doi.org/10.2118/87130-MS

[8] Wang H, Soliman MY, Towler BF. (2008). Avoiding drilling problems by strengthening the wellbore while drilling. 42nd U.S. Rock Mechanics - 2nd U.S.-Canada Rock Mechanics Symposium.

[9] Wang H, Soliman MY, Towler BF. (2007). Near wellbore stress analysis and wellbore strengthening for drilling depleted formations. Society of Petroleum Engineers - Rocky Mountain Oil and Gas Technology Symposium 5-16.

[10] Wang H, Soliman MY, Towler BF. (2008). Investigation of factors for strengthening a wellbore by propping fractures. IADC/SPE Drilling Conference, pp. 669-683. https://doi.org/10.2118/112629-MS

[11] Wang H, Soliman MY, Towler BF, Shan Z. (2009). Strengthening a wellbore with multiple fractures: further investigation of factors for strengthening a wellbore. 43rd U.S. Rock Mechanics Symposium \& 4th U.S. Canada Rock Mechanics Symposium, Asheville.

[12] Wang H, Soliman MY, Towler BF, Shan Z. (2008). Wellbore strengthening without propping fracturesanalysis for strengthening a wellbore by sealing fractures alone. International Petroleum Technology Conference 2:
1140-1155. https://doi.org/10.2523/IPTC-12280-MS

[13] Wang H, Soliman MY, Towler BF, Yao Z. (2016). Forming a seal independent of formation permeability to prevent mud losses-theory, lab tests, and case histories. IADC/SPE Drilling Conference and Exhibition, Fort Worth. https://doi.org/10.2118/178790-MS

[14] Van Oort E, Friedheim J, Pierce T, John L. (2009). Avoiding losses in depleted and weak zones by constantly strengthening wellbores. SPE Annual Technical Conference and Exhibition, New Orleans 26(4): 519-530. https://doi.org/10.2118/125093-PA

[15] Cali LS, Su CM, Liu JH. (2010). Analysis on pressurebearing capacity of leakage formation. ACRA PEREOLEI SINICA 31(2): 312-317. https://doi.org/10.1016/S1876-3804(11)60008-6

[16] Kang YL, Xu CY, Tang L. (2014). Constructing a tough shield around the wellbore: Theory and method for lostcirculation control. Petroleum Exploration and Development 41(4): 473-479. https://doi.org/10.1016/10.1016/S1876-3804(14)600616

[17] Wang G, Pu XL. (2010). Plugging mechanism of drilling fluid by enhancing wellbore pressure. Acra Pereolei Sinica 31(6): https://doi.org/10.7623/syxb201006024

[18] Yang P, Chen M, Jin Y, Zhu QQ, Wen H. (2012). Crack pressure bearing capacity model and its application to plugging of fractured formation. Chinese Journal of Rock Mechanics and Engineering 31(3): 479-487. https://doi.org/10.7623/syxb201006024

[19] Jia LC, Chen M, Tan QM, Sun Z, Wu SY. (2016). Key factors for inhibiting fracture propagation during leakage control under pressure. Petroleum Drilling Techniques 44(1): 49-56. https://doi.org/10.11911/syztjs.201601010

[20] Kumar A, Savari S, Whitfill DL, Jamison DE. (2010). Wellbore strengthening-the less-studied properties of lost-circulation materials. SPE Annual Technical Conference and Exhibition 2: 993-1005. https://doi.org/10.2118/133484-MS

[21] Savari S, Whitfill DL, Kumar A. (2012). Resilient lost circulation material (LCM): A significant factor in effective wellbore strengthening. SPE Deepwater Drilling and Completions Conference, pp. 390-396. https://doi.org/10.2118/153154-MS

[22] Miller ML, Scorsone JT, Whitfill DL. (2013). Development of unique equipment and materials with field applications to stop severe lost circulation. AADE National Technical Conference and Exhibition, Oklahoma City.

[23] Loeppke GE, Glowka DA, Wright EK. (2013). Design and evaluation of lost-circulation materials for severe environments. Journal of Petroleum Technology 42(3): 328-337. https://doi.org/10.2118/18022-PA

[24] Kageson-Loe, NM, Sanders MW, Growcock F, Taugbol K, Horsrud P, Singelstad AV, Omland TH. (2008). Particulate-Based Loss-Prevention Material-The Secrets of Fracture Sealing Revealed. SPE Drilling \& Completion 24(4): 581-589. https://doi.org/10.2118/112595-PA

[25] Sun QC, Wang GQ. (2009). Introductory theory of granule matter mechanics. China Science Press.

[26] Sun QC, Hou MY, Jin F. (2011). Granule matter physics and mechanics. China Science Press.

[27] Liu JY, Qiu ZS, Luo Y. (2015). Experimental study on 
lost circulation prevention of oil-based drilling fluid. Drilling Fluid \& Completion Fluid 32(5): 10-14. https://doi.org/10.3696/j.issn.1001-5620.2015.05.003

[28] Sun QC, Wang GQ, Hu KH. (2008). Thoughts on several key problems of granular material mechanics. Progress in Natural Science 18(10): 1104-1110. https://doi.org/10.3321/j.issn:1002-008X.2008.10.003

[29] Liu JY. (2016). Study on wellbore strengthening drilling fluid technology. China University of Petroleum.

[30] Wang ZH. (2014). The status and development direction of plugging technology for complex formation lost circulation. Sino-Global Energy 19(1): 39-48. https://doi.org/10.3969/j.issn.1673-579X.2014.01.007

[31] Zhang GY, Huang JJ, Zhang B. (2010). Equipment and method of formation pressure capacity. West-china Exploration Engineering 12: 82-84.

[32] Song BT, Liu Y, Xue Y, Wu FS. (2007). Study on loss circulation control test instrument in Jiangsu oil field. Drilling Fluid \& Completion Fluid 24(3): 24-26. https://doi.org/10.3969/j.issn.1001-5620.2007.03.007

[33] Lv KH. (2007). Study and application of lost circulation resistance and control technology during drilling. China University of Petroleum.

[34] Li XJ. (2011). Research on technology of enhancing wellbore resistance capacity by plugging fracture formation. Southwest Petroleum University.

[35] Wang G. (2012). Theory and technology on drilling fluids for wellbore strengthening. Southwest Petroleum University.

[36] Qiu ZS, Liu JY, Zhou BY, Bao D, Song DD, Xiao CC. (2016). Tight fracture-plugging mechanism and optimized design for plugging drilling fluid. Acra Pereolei Sinica 37(S2): 137-143. https://doi.org/10.7623/syxb2016S2017

[37] Kang YL, Yu HF, Xu CY. (2014). An optimal design for millimeter-wide fracture-plugged zone. Nature Gas Industry $\quad 34(11)$ : 88-94. https://doi.org/10.3787/j.issn.1000-0976.2014.11.012

[38] Savari S, Whitfill DL, Jamison DL, Kumer A. (2014). A method to evaluate lost circulation materialsInvestigation of effective wellbore strengthening applications. SPE Drilling and Completion 29(3): 329333. https://doi.org/10.2118/167977-MS

[39] Wang, K, Zhang HL, Zhang RH. (2015). Comprehensive assessment of reservoirs structural fracture with multiple methods in Keshen-2 gas field, Tarim Barin. Acra Pereolei Sinica 36(6): 673-687. https://doi.org/10.7623/syxb201506004 